\title{
Study on regional population forecast and endowment insurance
}

\author{
Xiaohong Cheng ${ }^{1,}$, Li Qi $^{2, b}$ \\ ${ }^{1}$ Beijing Wuzi University Beijing, China, Beijing, 101149, China \\ ${ }^{2}$ Beijing Information Technology College, China, Beijing, 100015, China \\ aemail:bj201801@163.com, bemail: liq@bitc.edu.cn
}

\begin{abstract}
Keywords: population structure transfer model; multiple regression; endowment insurance
\end{abstract}
\begin{abstract}
With the arrival of China's aging population, pension insurance system is also facing an unprecedented pressure. In this paper, through the population of each age stage of the Beijing city population prediction model is established, and by predicting the elderly population data, of endowment insurance and give advice.

Due to the implementation of the family planning policy in the $1980 \mathrm{~s}$, leading to the birth rate is at the beginning of the reform and opening up, dropped sharply, and modern medicine is quite developed, also make life expectancy extended, so the development of aging population, showing rapid growth trend. It is expected that in 2020, the elderly population will reach 4 million 500 thousand, accounting for $20 \%$ of the total population of Beijing, will enter the depth of the aging stage. However, with the advent of the era of aging, pension insurance system is also facing unprecedented pressure. Therefore, this paper combined with the actual situation of Beijing City, Beijing city based on quantitative forecast of future population age structure and population change, mainly is to introduce the concept of population transfer, changes in population structure established transfer model to explore the age of the population, while the new population model using multiple regression method to establish a model of two phase. According to forecast, after the prediction of the Beijing port structure analysis, finally explores the influence of demographic change, and pension insurance are PAYG system and fund accumulation system coexist, expanding the pension system coverage, more people are added to the labor pension system, delay retirement, let alone two-child policy etc. advice. Such endowment insurance in order to face the huge challenge of population aging.
\end{abstract}

\section{Introduction}

Since 1990 entered the aging society, the elderly population has increased year by year, at present, the elderly population in Beijing has entered a period of rapid growth, Beijing population aging has accelerated development trend, the development of the faster than ever. Aging is a major social issue which concerns the national economy and the people's livelihood and social stability. Is expected by the end of this year, Beijing resident elderly population will reach 350 million; by 2020 , this figure more will rise to 4.5 million, accounting for $20 \%$ of the total population, society has entered into the depth of the aging stage. From 2020 to 2030 will be the peak of population aging, after aging has slowed, but aging trend will continue. The basic characteristics of the aging in our country: 1 , up to the size of the elderly population, the aging of the population development speed; 2 , not the old rich first; 3, the aging of the population showing area, gender, urban and rural difference. Visible, the trend of aging population will give our country endowment insurance system brings the severe challenge and pressure. The constructed population prediction model, to describe the changes in the population structure of the future, in order to establish the quantitative basis for the analysis of Beijing city endowment insurance system.

Collection of endowment insurance fund includes: social insurance tax, social insurance or social insurance for paragraph form, usually by employers, employees and the state to bear. In most countries, the pension insurance fees by on-the-job worker according to a certain proportion of the income to pay, the national finance to guarantee role in the end. The mechanism of endowment insurance operation is to balance principle, according to the balance principle, we can fund raising 
model is divided into three types, namely: PAYG model, part of the accumulation mode, and total accumulation pattern. PAYG model refers to the same period on-the-job personnel payment to pay pensions for the retired generation insurance financial model. Accumulation mode refers to the payment completely accumulated in the past and earn interest income from providing insurance mode. China began to take the PAYG mode, social security costs of intergenerational transfer. This model is effective in the period of planned economy. But with the acceleration of population aging, as has become difficult to overcome the contradictions and the aging of the population is now closed. In order to meet the needs of the development of the market economy, China from the late 1890 s in cities and towns throughout the country established semi fund accumulation mode, in recent years, and carry out the expand the sources of funds and personal accounts of the pilot, in order to solve the problem of lack of funding.

\section{Research status}

At present, there are many experts and scholars on the issue of population prediction. It is usually divided into two kinds of forecasting methods, one is the scene prediction, the other is the probability prediction. There are two kinds of analysis methods, one is the regression analysis, the other is the grey system analysis. Jiang Zhenghua, through the matrix and iterative method, to create a JPOP prediction model. Deng Julong founded the grey system theory, a gray prediction model is built, but this model just study the time series model, and does not introduce other constraints. Luo Ronggui uses Matlab to establish BP neural network model to predict population. And the combination of logistic and gray prediction model to predict population.

In terms of prediction we have many models and the method to learning from abroad. Holland mathematician Verhulst found a population change model, which is the famous logistic model. Austria population prediction scientist Lutz, the use of system simulation to predict the population scene. These prediction models and methods are also very valuable.

\section{Population stage transfer model}

The 2005-2014 data on the population structure of a demographic transition model, different age stages of population data in the future.

\section{Data preprocessing.}

In this paper, all the data from 2005 to 2014 issued by the Beijing Municipal Bureau of statistics statistical yearbook and census data. In 2005 - 2014 years, in addition to the sixth national population census in 2010 , other years to take most of the sampling survey, and the data obtained by this method are not accurate, so it is necessary to actual population data is obtained by data processing. In this paper, we use the sample data divided by the total number of samples and then multiplied by the total number of Beijing City, the formula is as follows:

$$
\mathrm{p}_{f}=\left(p_{s} / p_{a 1 l_{s}}\right) * p_{B J}
$$

Among them, $\mathrm{p}_{f}$ for the actual number, $\mathrm{p}_{s}$ for the sample, $\mathrm{p}_{\text {alls }}$ for the total number of samples, $\mathrm{p}_{B J}$ for the total number of Beijing. 


\begin{tabular}{|c|c|c|c|c|c|c|c|c|c|c|}
\hline vear & 2005 & 2006 & 2007 & 2008 & 2009 & 2010 & 2011 & 2012 & 2013 & 2014 \\
\hline total & 1492.7 & 1538.0 & 1581.0 & 1633.0 & 1695.0 & 1755.0 & 1961.2 & 2018.6 & 2069.3 & 2114.8 \\
\hline $0-4$ & 38.6 & 45.7 & 48.8 & 55.0 & 64.6 & 69.3 & 68.6 & 77. 3 & 86.2 & 85.3 \\
\hline 5-9 & 46.7 & 51.7 & 48.8 & 47.0 & 48.9 & 51.6 & 50.0 & 55.3 & 60.4 & 66.7 \\
\hline $10-14$ & 63.3 & 59.6 & 59.3 & 55.2 & 50.9 & 53.6 & 50.1 & 51.1 & 56.9 & 48.2 \\
\hline $15-19$ & 122.9 & 111.1 & 107.1 & 109.8 & 94.3 & 91.0 & 107. 1 & 104.5 & 83.9 & 97.8 \\
\hline $2.0-2.4$ & 150.7 & 152.9 & 167.9 & 173.9 & 166.8 & 189.1 & 263.3 & 251.2 & 158.6 & 252.7 \\
\hline $25-29$ & 119.4 & 133.6 & 155.0 & 178.1 & 194.8 & 203.3 & 237.8 & 234.5 & 182.1 & 266.4 \\
\hline $30-34$ & 133.4 & 140.0 & 131.7 & 138.9 & 142.2 & 147.7 & 182.4 & 190.8 & 175.7 & 239.0 \\
\hline $35-39$ & 131.3 & 138.0 & 143.8 & 153.0 & 156.9 & 167.4 & 172.2 & 167.2 & 127.8 & 165.0 \\
\hline $40-44$ & 152.3 & 151.7 & 148.8 & 154.2 & 145.9 & 148.8 & 165.7 & 173.5 & 171.8 & 176.4 \\
\hline $45-49$ & 132.6 & 133.7 & 121.8 & 119.9 & 141.3 & 152.6 & 162.8 & 176.1 & 183.6 & 155.7 \\
\hline $50-54$ & 105.5 & 119.4 & 123.4 & 125.3 & 142.7 & 130.1 & 134.6 & 134.4 & 178.0 & 137.7 \\
\hline $55-59$ & 69.1 & 76.3 & 89.0 & 97.2 & 106.2 & 105.8 & 120.5 & 134.2 & 179.7 & 131.0 \\
\hline $60-64$ & 61.0 & 58.3 & 58.7 & 58.8 & 65.0 & 67.4 & 75.2 & 86.8 & 124.8 & 98.4 \\
\hline $65-69$ & 64.6 & 62.7 & 61.1 & 55.2 & 51.9 & 49.5 & 51.5 & 55.8 & 80.8 & 75. 1 \\
\hline $70-74$ & 50.1 & 51.6 & 56.4 & 52.0 & 55.9 & 54.5 & 50.5 & 50.2 & 73.5 & 50.0 \\
\hline $75-79$ & 29.8 & 30.2 & 33.5 & 33.7 & 36.2 & 43.8 & 38.6 & 41.3 & 72.2 & 38.3 \\
\hline $80-84$ & 21.5 & 21.5 & 25.8 & 25.7 & 30.3 & 29.6 & 30.3 & 34.4 & 73.0 & 31.1 \\
\hline
\end{tabular}

Table 1 population of all ages in 2005-2014

\section{The definition of population transfer rate}

Population transfer refers to people of a certain age with the increasing of age and transferred to another age group, such as population aged 0-4 years after five years will be transferred to the 5-9 age, five years after the most population will decrease over a population. This is because death or spot check error and error. In this paper, the rate of the transfer of each age group is presented as a transfer rate.

$$
r_{i, j}=\left(p_{i+1, j+5}-p_{i, j}\right) / p_{i j}
$$

$i$-on behalf of a certain age, (0-4 years old) for the first phase, (5-9 years old) for the second phase; $\mathrm{j}$ - express time, $\mathrm{r}_{i, j}$-population transfer rate.

\section{Calculate the population transfer rate of 2004-2009}

\begin{tabular}{|c|c|c|c|c|c|}
\hline Age group & ri, 2005 & ri, 2006 & ri, 2007 & ri, 2008 & ri, 2009 \\
\hline $40-44$ & 0.00182 & 0.07317 & 0.18381 & 0.12525 & 0.06682 \\
\hline $45-49$ & -0.01889 & 0.00673 & 0.10330 & 0.12160 & -0.02550 \\
\hline $50-54$ & 0.00363 & 0.00921 & 0.08734 & 0.10905 & -0.08185 \\
\hline $55-59$ & -0.02493 & -0.01442 & -0.02469 & -0.00858 & -0.07350 \\
\hline $60-64$ & -0.18820 & -0.11664 & -0.04924 & 0.05014 & 0.15483 \\
\hline $65-69$ & -0.15572 & -0.19458 & -0.17834 & -0.10093 & -0.03659 \\
\hline $70-74$ & -0.12638 & -0.25194 & -0.26832 & -0.18505 & -0.31501 \\
\hline $75-79$ & -0.00840 & 0.00331 & 0.02643 & 0.08687 & -0.14055 \\
\hline 80 above & -1.00000 & -1.00000 & -1.00000 & -1.00000 & -1.00000 \\
\hline
\end{tabular}

Table 2 2005-2009 partial population transfer rate

By the table we can see for example decreased in 2005 aged 45-49 population transfer to 2010 50-54 years old. This is because the population death or statistical errors, and individual phase transfer rate data is relatively large, which is usually the opposite of common sense of, but because of population data is Beijing resident population data (the resident population is that in Beijing the actual living more than half of the population), so non household population mobility is relatively large, so will appear individual relatively large numerical. Of course there are statistical errors or pre concealed data, later added.

\section{Research on endowment insurance}

Through the above prediction, we can get the change of population age structure with time. That is to say Beijing population center of gravity shifted to the elderly population. The city of Beijing has entered the aging society, it is for the endowment insurance brought no small pressure. The generally believe that the elderly population over the age of 60) accounted for the ratio of the total population of more than $10 \%$ can be counted into the aging society, the aged population in Beijing 
accounted for the total population ratio usually in $12 \%$ to $15 \%$ floating. And because of the relatively large population base in Beijing, so the number of growth is also very alarming. At the same time, with the increase in the proportion of elderly population, the growth rate of the elderly is also very fast. Therefore, the seriousness of the aging of Beijing city and to bring the difficulties of pension insurance.

According to the data, in 2012 the proportion of the elderly population in Beijing household registration for the first time exceeded $20 \%$, reaching $20.3 \%$. The report said that as of the end of 2012 , the city residence of the elderly population over the age of 60 for 2.629 million people, than last year increased 15 million people, accounted for 20.3 percent of the total population. "The equivalent of every 4 men" lift "an old man. Beijing elderly dependency ratio was $29.4 \%$, an increase of 1.8 percentage points over the previous year. The number means that raising an old man needs 3.4 labor, the burden of social care in the increase. By 2040, the city's aging population will reach 5 million 600 thousand, equivalent to every two people, "lift" an old man.

In order to meet the needs of the development of the market economy, China from the late $1890 \mathrm{~s}$ in cities and towns throughout the country established semi fund accumulation pattern. The aging of the population in the period, to receive more than the same period the number of working population the number of pension, so there will be a deficit and the current situation is not serious, but rapid ageing, or will bring certain burden. Although in recent years and carried out to expand the sources of funding, personal accounts of the pilot, in order to solve the problem of insufficient funding sources, combining the two systems, but young employees not only to bear their own pension accumulation, but also bear the pensions of retired workers, it also gives young employees bring huge pressure, is not conducive to long-term development, so at present, the implementation of the PAYG system is not suitable for the requirements of endowment insurance under the situation of aging. And from 2001 began to implement the reform program, PAYG part by the enterprise bear, fund accumulation in part borne by individuals ", compared to total cash pay as you go system, greatly reducing the pressure on the staff.

The aging of the population should be linked with the economic development needs, also need through financial planning to achieve the supplementary pensions, for endowment insurance fund "unload baggage". Some experts pointed out that by 2035 China will face two taxpayers to support a pension recipient. Pension after the merger, China faces the trillion cost gap, it is especially necessary and urgent to delay retirement. Obviously, the implementation of the delay retirement policy, the main reason is to ease the gap of pension insurance.

\section{Conclusion}

Through the analysis, this paper argues that completely cash cash system will lead to pension contribution rate gradually increased, on-the-job worker pressure greatly, so the PAYG system and fund accumulation system coexist will greatly reduce the pressure of on-the-job worker, adapt to the needs of the development of the aging of the population. In addition, more people are added to the labor pension system, also can make pension funds more abundant. 2015 during the two sessions, the delay in retirement issues of concern. At present, the aging of the population of the pension fund will face enormous pressure in the future balance of payments. If the retirement age for men to 65 years old, women referred to the age of 60 . Is more than 5 years of pension insurance, less 5 years of pension. Experts considered the posting, the retirement age for each delayed for up to a year, the national pension fund can increase of 40 million yuan, 160 billion yuan, slow down the fund gap of about 200 billion yuan, and delay retirement policy is quick and convenient and can be said to serve multiple purposes. Beijing city and the current implementation of the two-child policy alone can also prevent aging more serious. Only in all aspects of the integration, in order to better solve the problem of aging society pension. The aging of population is a major social problem, which is related to social stability, harmony and development. Pension problems cannot jump to escape reality alone to study and solve, we should consider more about the population problem, such pensions to cure. 


\section{References}

[1] Lv Shengge Xuan Danping, the aging of population in Beijing in March 2012 twenty-ninth [C] coefficient prediction statistics on volume third.

[2 Meng Chao based on the Leslie matrix and time series analysis of population prediction research [J] 2012.04.

[3] Liu Suo based on population prediction model of China's endowment insurance research [D] 2013.05.

[4] Wang Shaofeng Beijing endowment insurance model and Simulation Research [D] .2011.08.

[5] Su Changgui Hunan province future population forecast and development trend analysis [J] 2013.02. 